\title{
Vermont Cancer Center at the University of Vermont
}

National Cancer Institute

\section{Source}

National Cancer Institute. Vermont Cancer Center at the University of Vermont. NCI

Thesaurus. Code C39561.

The Vermont Cancer Center is committed to innovative cancer research, life-saving prevention and treatment programs, public education and scientific collaboration, and serves to influence standards of cancer prevention, screening, diagnosis and care. It is part of the University of Vermont College of Medicine and has a clinical partnership with Fletcher Allen Health Care. 